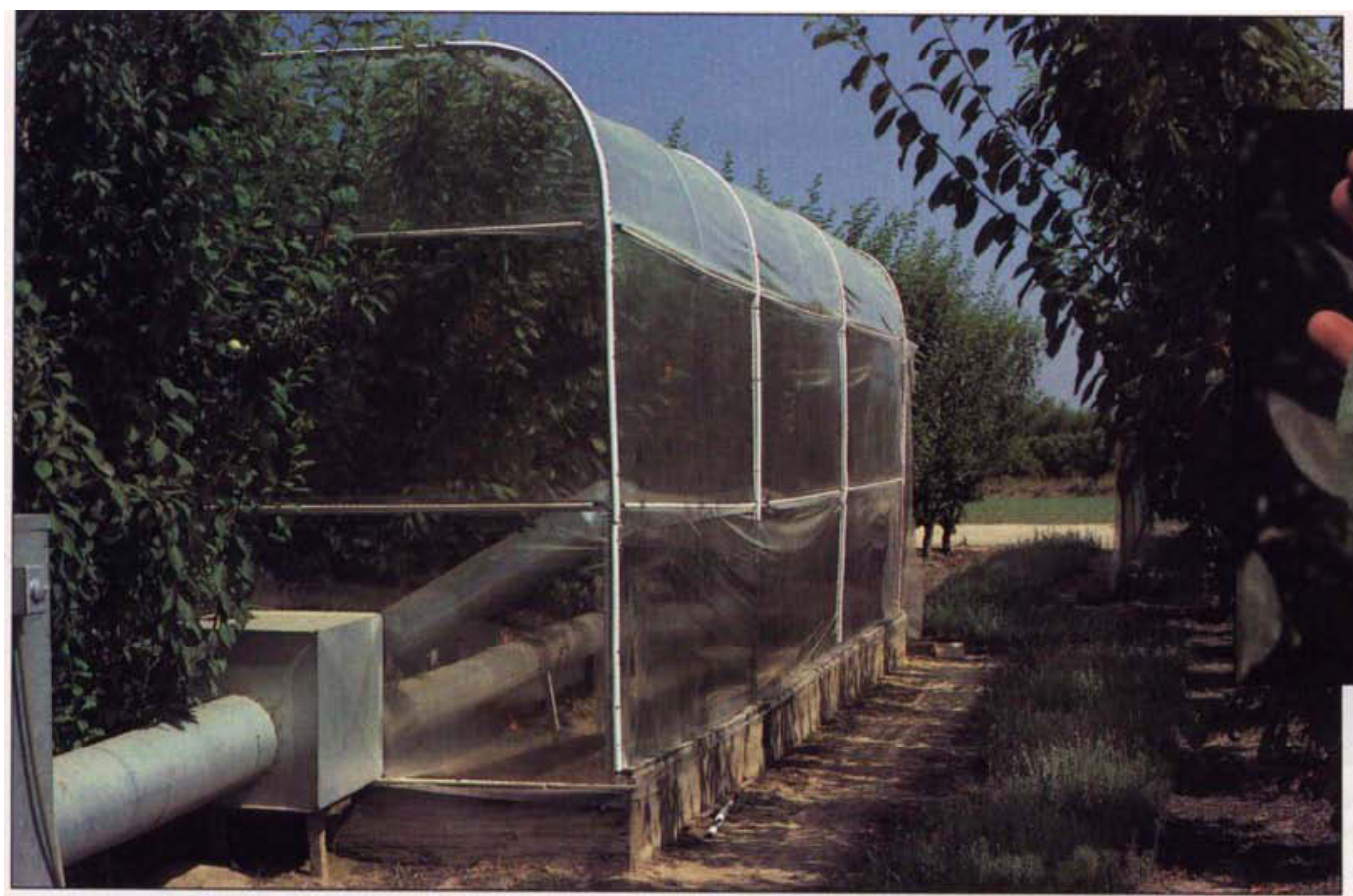

\title{
Ozone air pollution increases spray oil phytotoxicity
}

William A. Retzlaff

William W. Barnett

$\square$

Larry E. Williams

$\square$

Theodore M. DeJong
A Phytotoxic spray-oil injury on 'Casselman' plum foliage.

Field-grown 'Casseiman' plum trees were exposed to three different treatments of air pollution in open-top chambers. Scientists observed the severity of spray oil injury to trees in each treatment.
In 1992, a moderate to severe outbreak of spider mites was found in 'Casselman' plum trees exposed to three atmospheric ozone air pollution treatments. Five days after spraying with a summer application of a medium grade oil, phytotoxic effects were observed on the foliage of trees exposed to ambient or higher atmospheric ozone air pollution. This research indicates that ozone air-pollution stress may predispose plants to increased phytotoxicity from summer olls.

Petroleum oil sprays have been used for pest control for more than 100 years. Used properly, summer oil application can effectively control spider mites (Tetranychus spp.). However, when heavy grades, high rates or impure oil sprays are deposited on some foliage, they may penetrate and block stomata, kill cells and lead to yellowing or chronic foliar injury. In previous experiments, UC researchers
(Riehl et al.) found depressed transpiration of 'Bearss' lime (Citrus latifolia Tan.), 'Eureka' lemon (C. limon [L.] Burm. f), and 'Valencia' oranges (C. sinensis [L.] Osbeck) for up to 5 weeks following application of a California medium grade oil. Generally, summer oils should not be sprayed during hot weather, low relative humidity or on trees suffering from water stress or other stresses.

During the 1992 growing season, a moderate to severe outbreak of spider mites occurred on field-grown

'Casselman' plum (Prunus salicina Lindel.) trees exposed to three atmospheric ozone air pollution treatments in open-top chambers. Visual observation indicated mite levels were uniform throughout all chambers. To control the outbreak, a single application of a commercially available oil was made on June 12, 1992. The following report details conditions of the plum air pollution study and the phytotoxic effects that developed as a result of the spray treatment.

\section{Ozone treatments}

Nursery stock of 'Casselman' plum on 'Citation' (Prunus hybrid) rootstock was planted April 1, 1988, in an experimental orchard at the Kearney Agricultural Center near Fresno. Trees and rows were spaced 6 feet and 14 feet, respectively. Trees were trained to an open-vase shape, with other cultural practices similar to those used for the commercial production of plums.

Ozone treatments included charcoal-filtered air, ambient air, and ambient air + ozone. Treatments were randomly assigned to open-top chambers measuring 10 feet wide by 24 feet long and 10 feet high. Each chamber contained four plum trees, with five replications of each treatment in separate chambers. A computer-controlled monitoring system was used to monitor ozone concentrations in the chambers from April 8 to November 1, 1992.

Air for the ambient air and ambient air + ozone was blown directly into each chamber. Air for charcoal-filtered chambers was drawn through acti- 


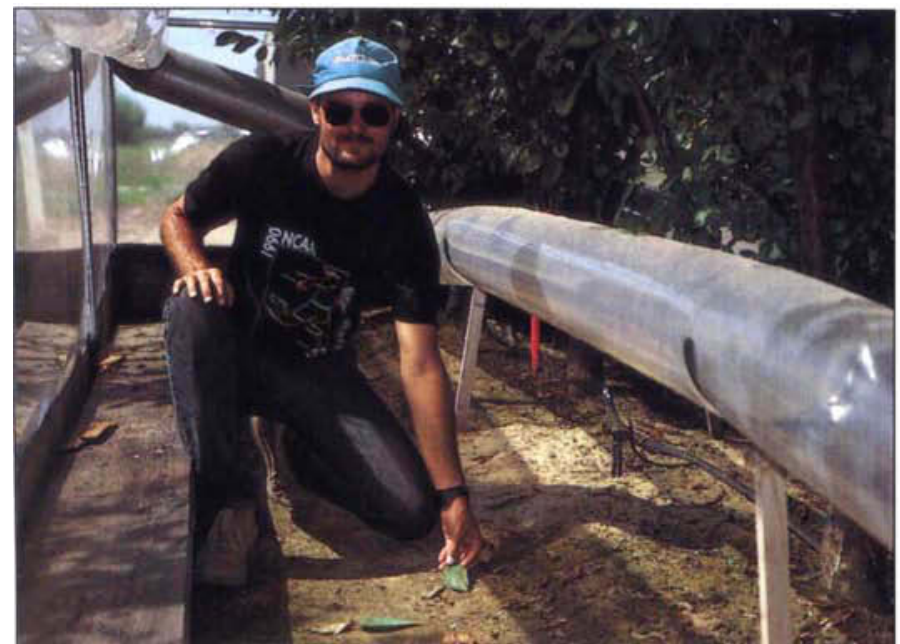

William Retzlaff indicates the relatively low level of leaf abscission for oil-damaged 'Casselman' plum foliage in a charcoalfiltered air treatment chamber.

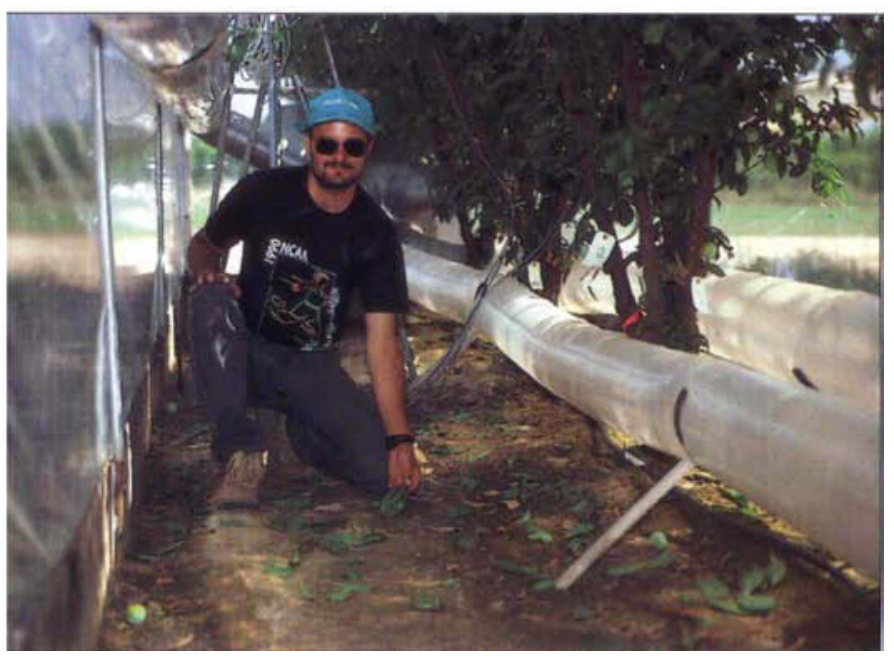

Oil-damaged 'Casselman' plum foliage abscission increased in an ambient air treatment chamber. vated charcoal filters before delivery into chambers. Additional ozone for the ambient air + ozone treatment chambers was generated from dry ambient air, using a Griffin ozone generator, then added to the delivery air stream. The ozone generator was computer-automated to adjust the ozone output during the day, depending on ambient atmospheric ozone concentration. This system resulted in ozone concentrations approximately $55 \%$ of ambient in the charcoal-filtered air chambers and $180 \%$ of ambient in

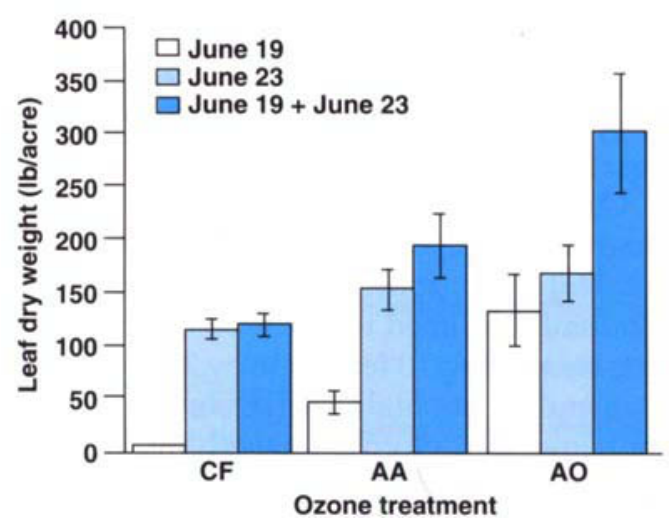

Fig 1. Dry weight of abscised leaves on June 19 and 23, 1992, and the sum of the two dates, from 'Casselman' plum trees exposed to three atmospheric ozone concentrations and sprayed with Volck Supreme oil on June 12, 1992. CF = charcoalfiltered air, 24 ppb ozone; $A A=$ ambient air, 44 ppb ozone; $A O$ = ambient air + ozone treatments, 81 ppb ozone. the ambient air + ozone chambers for the exposure period, April 8 to June 12, 1992.

\section{Spray application}

Volck Supreme oil was tank-mixed ( $1 \mathrm{gal} / 100 \mathrm{gal}_{2} \mathrm{O}$ ) in an Air-O-Fan model GB34 sprayer. It was applied June 12 between 9:30 and 10:30 a.m. PDT (a cooler, less humid time of day) by a certified pesticide applicator using a hand-held sprayer.

Temperature and humidity at the time of spray application were obtained from a California Irrigation Management Information System weather station located 0.3 miles $(0.5$ $\mathrm{km}$ ) southeast of the plum orchard.

\section{Leaf abscission}

We quantified abscission on June 19 and 23 by collecting leaves that had fallen to the ground in each of the treatment chambers. Collected leaves were dried in a forced-air oven at $150^{\circ} \mathrm{F}\left(66^{\circ} \mathrm{C}\right)$ until no further weight change occurred. Leaf-fall data was collected at regular intervals throughout the remainder of the growing season to determine final foliage biomass. The percent of foliage remaining on the trees was calculated after phytotoxic leaf abscission ceased on June 23 .

\section{Visible spray oil injury}

Spray oil injury was visible in all ozone treatments; however, injury was more prevalent on trees exposed to the higher atmospheric ozone concentrations. Phytotoxic effects were first observed on foliage June 17 , five days after spray application. Foliar injury first appeared as darkened spots on the adaxial leaf surface. This injury was spread uniformly throughout the tree canopy, but was not evident on all foliage. Phytotoxic oil injury differs in appearance from foliar injury caused by increased atmospheric ozone air pollution, which occurs on older foliage first, and consists of chlorotic spots and yellow flecking.

We have previously documented premature leaf abscission for 'Casselman' plum trees following 2 months of exposure to atmospheric ozone concentrations $>90 \mathrm{ppb}$. However, ozone-induced 'Casselman' plum foliage abscission had never been observed at the lower ozone concentrations used here. In our study, more foliage fell (measured by dry weight collected on June 19) from trees exposed to 44 and $81 \mathrm{ppb}$ ozone than from trees exposed to $24 \mathrm{ppb}$ ozone (fig. 1).

Foliage abscission was greatest across all ozone treatments between June 19 and 23. After June 23, foliage abscission ceased and no additional visible symptoms from spray oil injury appeared on the remaining plum foliage. Final dry weight of foliage that had fallen by June 23 was higher for trees exposed to 44 or $81 \mathrm{ppb}$ ozone than for those exposed to $24 \mathrm{ppb}$ 


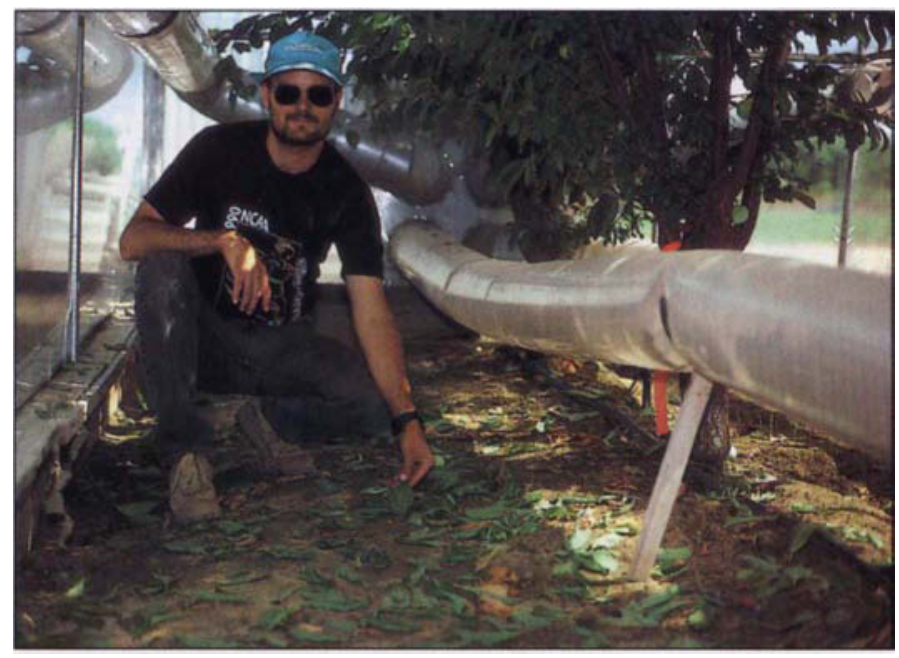

Oil-damaged 'Casselman' plum foliage abscission was greatest in an ambient air + ozone treatment chamber.

ozone. The amount of foliage remaining on plum trees was further reduced after June 23 with an increase in atmospheric ozone concentration. Specifically, $97 \%, 95 \%$ and $93 \%$ of the final leaf biomass remained on the trees in the charcoal-filtered air, ambient air, and ambient air + ozone treatments, respectively.

Similar phytotoxicity has been described following applications of oils to foliage of fruit trees during periods of high temperatures $\left(>90^{\circ} \mathrm{F}\left[32^{\circ} \mathrm{C}\right]\right)$, low relative humidity $(<20 \%)$, or when trees are stressed before spraying. Previously, we found that leaf net photosynthetic rate and trunk cross-sectional area growth of 'Casselman' plum trees were reduced following 2 months of exposure to atmospheric ozone concentrations $>90 \mathrm{ppb}$, indicating that trees growing in increased ozone air pollution are stressed. Further, leaf net photosynthetic rate of 'Casselman' plum trees in ambient air and ambient air + ozone treatment chamber measured June 22 were $8 \%$ and $16 \%$ lower, respectively, than the charcoal-filtered air trees.

We do not know whether stress caused by the spider mites or the interaction between mite feeding and ozone stress influenced the degree of oil-induced phytotoxicity. However, if spider mites alone were the cause, the observed phytotoxicity should have been the same in all ozone treatments.

In this study, temperature and relative humidity at the time of spraying and later in the day (table 1) were well within recommended limits. The only visible sign of stress was mites, and visual estimation of mite populations indicated that infestation was uniform across all treatments. However, plum trees had been exposed to different at-
TABLE 1. Air temperature, relative humidity, and ozone concentration at the time of spray application and at time of peak daily ozone concentration, June 12, 1992.

\begin{tabular}{|c|c|c|c|c|c|}
\hline \multirow[b]{2}{*}{ Time } & \multirow{2}{*}{$\begin{array}{c}\text { Air } \\
\text { temperature }\end{array}$} & \multirow{2}{*}{$\begin{array}{l}\text { Relative } \\
\text { humidity }\end{array}$} & \multicolumn{3}{|c|}{ Ozone concentration } \\
\hline & & & CF & AA & AO \\
\hline & ${ }^{\circ} \mathrm{F}$ & $\%$ & ....... & $p p b$ & ......... \\
\hline $\begin{array}{l}10 \text { a.m. PDT } \\
\text { spray application }\end{array}$ & $65.7 \dagger$ & $48 \dagger$ & 18 & 26 & 36 \\
\hline $\begin{array}{l}4 \text { p.m. PDT } \\
\text { peak ozone }\end{array}$ & 73.4 & 39 & 25 & 41 & 95 \\
\hline Season & & & 24 & 44 & 81 \\
\hline
\end{tabular}

" $\mathrm{CF}=$ charcoal-filtered air, $\mathrm{AA}=$ ambient air, and $\mathrm{AO}=$ ambient air + ozone, respectively.

$\dagger$ Meteorological data were not being monitored inside the open-top chambers during the spray application period. However, air temperature and relative humidity were monitored inside the chambers at other times during this 5-year study.

Air temperature inside the chamber was never measured to be more than $4^{\circ} \mathrm{F}$ different than the outside air temperature and relative humidity inside the chamber was never measured to be more than $2-3 \%$ different than the outside relative humidity. Therefore, the conditions inside the chamber would not have exceeded the recommended application conditions for this summer oil spray.

‡ Seasonal average (12-hour mean) ozone concentrations for April 8 to June 12, 1992. mospheric ozone air pollution treatments for more than 2 months before spraying, and atmospheric ozone concentrations differed at the time of spray application (table 1). Plum trees exposed to increased atmospheric ozone air pollution showed increased phytotoxicity following spraying, indicating ozone air pollution stress may predispose plants to phytotoxicity from spray applications of summer oils. We do not know whether the reduction in foliage remaining on the trees (up to $7 \%$ in the $81 \mathrm{ppb}$ ozone treatment) as a result of spray oil phytotoxicity was great enough to affect the productivity of these plum trees. However, there have been previous, but unexplained episodes of spray oil phytotoxicity (W.W. Barnett and J.E. Dibble, personal communication) in the San Joaquin Valley, which may be linked to the atmospheric ozone air pollution stress the region has experienced.

W.A. Retzlaff was Postdoctoral Research Associate, Department of Viticulture and Enology, UC Davis, stationed at Kearney Agricultural Center, and is currently Postdoctoral Associate, Boyce Thompson Institute for Plant Research at Cornell University, Tower Road, Ithaca, NY; W.W. Barnett is former Area IPM Farm Advisor, UC Cooperative Extension, Kearney Agricultural Center; L.E. Williams is Professor, Department of Viticulture and Enology, UC Davis, stationed at Kearney Agricultural Center; and T.M. Dejong is Professor, Department of Pomology, UC Davis.

We thank P. Biscay, W. Yang, and $N$. Ebisuda for technical assistance; Dr. C.G. Summers and Dr. J.E. Dibble for critical manuscript review; and J. Coviello for word-processing assistance.

This study was funded in part by a grant from the California State Air Resources Board. The statements and conclusions of this report are those of the University of California and not necessarily those of the California State Air Resources Board. The mention of commercial products, their source, or their use in connection reported herein is not to be construed as either an actual or implied endorsement of said products. 